Hyperreality in the Black Mirror Episode Shut Up and Dance

\author{
Muhammad Daniswara Wibowo Putra
}

Universitas Sebelas Maret

Author Note

${ }^{1}$ Author is a student of English Department, Faculty of Cultural Sciences, Universitas Sebelas Maret, Jalan Ir. Sutami 36A, Surakarta, Indonesia (e-mail: daniswaracq@gmail.com) 


\begin{abstract}
This research analyzes how a Black Mirror episode entitled Shut Up and Dance explores the idea of simulation crisis of the main character has to cope as the episode represents. This study uses Jean Baudrillard's theory of Hyperreality and Baudrillard's semiotic approach to scrutinize the episode signs and symbols of how an individual is treated by society by means of their behaviors and purposes. The result shows that in Shut Up and Dance, the show creator presents the concept of Hyperreality by showing the audience the declines of the main character's humanity, which eventually reduces to a mere symbol in the bigger picture, by delivering signs and symbols to the audience that indicates the process and symptoms of Hyperreality.
\end{abstract}

Keywords: Hyperreality, Black Mirror, Charlie Brooker, Shut Up and Dance 


\section{Hyperreality in the Black Mirror Episode Shut Up and Dance}

Since their invention, the internet and social media by proxy, have always been perceived as a double-edged sword. On the one hand, the state of being connected to the social network is seen as a positive way to be aware of current events and to keep in touch with an individual's social circle without being bound to time and place. On the other hand, the addiction or dependency towards social media and the possibility of social media being misused concern many of its users.

This concern and paranoia surrounding technology are manifested in the Netflix original TV series, Black Mirror. According to its creator, Charlie Brooker, Black Mirror is meant to be a reflection of how the current modern society treats its technology (2016). Black Mirror itself was produced so that its audiences are aware of the potential danger technology possesses. The danger revolves around how technology affects personal life as well as interpersonal relationship (Boren, 2015). Despite many Black Mirror's world and its message of danger lurking in technology are seen to occur in the future, it may as well be our current threat. The Black Mirror's message has drawn many interests due to its ability to present today's technological threat while also romanticizing it as a threat of a dystopian future. For example, in the episode Be Right Back or Crocodile, it is technologically possible to turn a human's eye into a functioning recording camera or in San Junipero episode, it is possible to transfer an individual's consciousness into a virtual reality (Sculos, 2017).

According to Singh (2014), Black Mirror's world is a distortion of image controlling society and individuals to the highest degree that individuals can no longer differentiate which is reality and which is just a representation of an object in reality. He has also added that most of the main protagonists in the Black Mirror universe are so immersed in the myth and symbols as presented by the technology, leading them to misrecognize relationships and purpose of individuals as proposed by Baudrillard theory of Hyperreality in his book Simulation and 
Simulacra (1981). He argues that this phenomenon as a negative effect of the social controls is a byproduct of technology information.

Therefore, it could be concluded that many episodes of Black Mirror concern with the concept of other-worldly concept of virtual reality -from the possibility of uploading consciousness to a computer to the possibility of virtual corporal punishment. However, Shut Up and Dance episode is an odd exception. It stands up in itself for how the concept of Hyperreality is independently presented in the episode. This unique episode has distinction in its representation of its dark tones and its subliminal message because the technologies imagined in the episode are not too far-fetched from the real world nor a romanticized version of contemporary technology. Consequently, the circumstances and dilemma of Shut Up and Dance are even more real and possible than any other Black Mirror episode as Sculos (2017) argued.

The Shut Up and Dance episode revolves around a socially awkward teenager named Kenny. On one typical day, Kenny comes home to find out that his sister has borrowed his laptop without his prior consent. Unfortunately, she accidentally downloads a virus. Then, Kenny downloads an antivirus program and seemingly succeeds in exterminating the virus. Unknown to him, a hacker manages to gain unauthorized access to his computer software and thus blackmails him into doing random questionable tasks ranging from simply delivering a cake to criminal tasks like robbing a bank or fist fighting to death. If he refuses to do the tasks, the hacker threatens to spread captured pictures of him masturbating, which he does after downloading the program, to all his contacts. In his journey to complete the tasks, he meets people who have had similar situation as his. This means that the hacker's ordeal happens to Kenny and to an unspecified number of people simultaneously.

After doing gruesome task to entertain the hackers, despite the promise that if he follows the instructions the picture will not be published, the picture is sent to Kenny's contacts and the authorities. At this point, the audiences realize that Kenny is, in fact, a pedophile and he has 
been going through a great length of completing the tasks because he has not wanted people to know that he has been masturbating to child porns.

Shut Up and Dance episode examines human beings' behavior and what it means in a society heavily oriented by technology. The episode explores vigilante justice as well as control and surveillance in a society where access to internet becomes easier to obtain. As Black Mirror is intended to reflect how we mistreat our technology (Robinson \& Brooker, 2016), the prior studies on this show often treated the episodes as a reflection of society. The show is being portrayed as a reflection of how current society live and misuse the perks provided by technology (Sculos, 2017). Prior study by Nolte-Odhiambo (2019) explores Shut Up and Dance through child-as-victim, how it affects maturity and age. Therefore, this research is focused on how the episode reconstructs the negative effects of the technology implementation as a tool to dictate human's ideas and behaviors.

This research aims to analyze how Shut Up and Dance represents Baurdrilard's concept of Hyperreality as a form of social control as argued by Baudrillard in his book -Simulation and Simulacra. Since the episode narrative has presented rich representations of the internet as the simulacrum world and the influence of the internet chat rooms in creating hyperreal world, this research uses narrative analysis to explore how the episodes presents the signs and symbols of physical reality and virtual reality co-mingle and blend together that might affect an individual's perception of reality.

\section{Method}

The data source of this research is Shut Up and Dance episode and the data collected are in the form of scenes and their meanings and implications by using purposive sampling method to support the research's purpose. The data were collected through watching the video in the Netflix's streaming service from the anthological series created by Charlie Brooker, Black Mirror's third episode of season three entitled Shut Up and Dance. The data are symbols such as visual and literal signs, dialogue and overall circumstances in the episode. The data were 
acquired by means of a few steps: first, watching Shut Up and Dance while making necessary notes; second, building points and arguments surrounding the hypothesis; third, going back watching Shut Up and Dance while taking necessary screenshots to back up the arguments and re-checking some facts about the episode. The data which are in the form of signs, symbols and movie-making techniques were analyzed to find out all of its implications.

This research applies narrative analysis to uncover the meaning of signs and symbols as being meant by Baudrillard in his theory of Hyperreality influencing individuals' real life and drive them into hyperreality. Different from structuralist approaches such as Barthes', which provides rigid categories with pre-determined meaning (Barthes, 1964), Baudrillard's poststructuralist view does not hold the same value system towards signs and symbols. Instead, Baudrillard believes a narrow pre-determined value can be challenged and deconstructed (Genosko, 2010). This idea of challenging what a sign or symbol should represent and what it actually represents is his primary concern, since it could lead to construe the meaning as imagined by individuals. It gives the freedom of interpretation through contextualizing the data to the recent situation of the impact of communication technology to the life of the people. It could also lead to draw an assumption of the creator's criticism to control system as a byproduct of information and network technology.

\section{Result}

Baudrillard (1981) argues that an individual who lives in a simulation has his/her main purpose and value in life in the form of signs and symbols rather than the real thing. The power of information they immerse in appears to be the most valuable substance to the core of their humanity. Shut Up and Dance explores this idea for its main premise is that an individual action is being controlled by the device that distributes information which is ironically meant to be controlled by the user.

One could argue that it is not the act itself that causes Kenny's downfalls but rather the 
information readily stored in his device which is capable of being shared. Meanwhile, the act of hacking itself is widely regarded as illegal and there are regulations and laws covering the breach of privacy such as the data protection act and thus the internet users are expected to act carefully in browsing the network.

Despite all of Kenny's preventative measures in ensuring that no one is near him in the house by installing a lock on his doors and deleting the evidences, it does not guarantee a complete isolated privacy or an escape since the network is open and it memorizes every action taken in its space (Kimble, 2008). Kenny's entire ordeal happens because his action on the internet is transcended into real life, correlating to the theory coined by Manuell Castell in his book, Network Society (1996).

This course of action represents how the power of the technology reaches beyond what is bound in reality. The lock on the door and the camera frame that keeps getting closer and closer to Kenny in the bedroom scene represent how suffocating it is to keep a wall around oneself in order to have some sense of privacy although, by the end of the episode, it all turns out to be for nothing.

The control that the technology has over Kenny is at first displayed when Kenny receives an email from an unknown address. The email was about the demand proposed by the hacker which emphasizes the idea of the power the hacker has over him. This is a very terrifying moment given how vulnerable this situation is now that he is at the hacker's mercy. He closes the laptop in horror and feels being exposed not only because of somebody's watching him performing a sexual act but also a fear of what might happen should somebody finds out what he has been doing.

The hacker realizes that Kenny's circumstances of not being famous, masses exposure would not be the best option, and therefore, alerting everybody in his social circle would be a better punishment since that his contact is the people that he keeps in contact with most, making him the biggest social outcast, a prisoner of social discourse. This imagery is expressed when 
the camera went through 180 degrees from his desk to his bed. A disorienting movement of the camera to emphasize the lack of space he truly has. Like Kenny's being a prisoner, the spaces around him get smaller as the frame around him is gradually getting closer and closer, which indicates his paranoia becoming more rampant.

The next scene, Kenny goes to work in the following day, the camera once again demonstrates his paranoia by stalking him around the area of his workplace with rampant movement. He then receives a text with a command which indicates he is somehow turned into a robot. The text's phrase "You have been activated" indicates that the hacker turns his power switch on and now Kenny must obey the commands of his master. Even his long bike ride scene en route to his tasks is interacted with GPS shots, indicating that he is being reduced to a symbol to be used and abused by the hacker. This symbolizes that in the grand scheme, the hacker is not seeing Kenny as a person but rather as a symbol in a computer that can be controlled, manipulated and coerced according to the hacker's will.

In his way to fulfilling the hacker's demand, Kenny meets a fellow person being blackmailed by the hacker named Hector. When Hector starts to question the hacker's power over the pair, the hacker is proven to have access to his or her victim devices which are indicated by his or her ability to provide even the most private information that Hector and Kenny have had. This finding creates a high level of anxiety within the pair. When they fail to pinpoint the culprit or a solution to their problem, they start to suspect anyone to be the one behind the text messages. The lack of culprit makes the audience question whether the characters are actually being monitored throughout their activation period or the commands are enough to control them alone.

As the pair become warrier and psychologically damaged by the hacker, the quicker they grab their phones when it rings, indicating a new threat haunts them. When Kenny is forced to rob a bank, the hacker puts Kenny in a crime situation outside his bedroom, outside the security he has built for himself and outside the pleasure he has got from his illicit activities, that all 
have escalated the situation into a new level.

After the bank robbery, Hector drops Kenny off at a road on the edge of the woods where Kenny is going to meet a man like himself, who is later on revealed as a pedophile blackmailed by the hacker and armed with a camera drone. The horrific buzzing sound of the drone adds the symbolic use of pins in the digital map used by the hacker to indicate where Kenny needs to go, and it symbolizes as if Kenny is being cornered and/or stung by the hacker.

With the drone up above recording the activity of the two, the hacker then instructs both men to fist fight. After the fight, with Kenny being bloodied and beaten, it was revealed that Kenny is a pedophile and is caught masturbating to child porn by the hacker. The hacker contacts the authorities and has sent Kenny's secret to all his contacts, and therefore the hacker is breaking the promise that if Kenny fulfils the hacker's demands, the video will be kept secret.

Throughout the episode, the audience is led to assume that the hacker is playing a game to teach all these awful people a lesson not to do these awful things again, in Kenny's case masturbating to porn. The audience is led to believe that Kenny's reactions to the hacker's demand are over the top, given how young and awkward he is, though his determination to cover up his mess is somewhat strong and admirable. However, this proves ultimately pointless as the hacker is relishing in Kenny's nihilistic punishment, symbolized by the troll face that Kenny receives via a text, giving the context of trolling or ridiculing a whole new meaning.

At the end, 'Exit Music,' a song by Radiohead is played indicating that Kenny has been a naughty boy for his actions and will not do the same actions again and be a good boy, which turns out to be for nothing.

[Verse 1]

Wake from your sleep

The drying of your tears

Today we escape, we escape

Pack and get dressed 
Before your father hears us

Before all hell breaks loose

[Verse 2]

Breathe, keep breathing

Don't lose your nerve

Breathe, keep breathing

I can't do this alone

The song emphasizes on breathing and inescapable environment which resonate well with the plot of the episode, indicating Kenny's desperation and eventual downfall in his life. In reference to Hyperreality (Baudrillard, 1981), the song symbolizes that the power of the signs and symbols is suffocating and inescapable that the best option for individuals such as Kenny is to keep calm and follow the rules of the simulated reality he is taking part in.

The title Shut Up and Dance specifically refers to the controlling and performative nature of the hacker's exercise of power. The word 'shut up' from the title Shut Up and Dance refers to Kenny's inability to confine his predicament to anybody as well as his state of being powerless to challenge or even protest the hacker's demand and perform the orders sent to him through his phone. Meanwhile, the word 'dance' from the title refers to the heinous, inhumane, humiliating activities that the hacker has blackmailed Kenny to do. Dance is in reference to him being given a set of behavior and instructions like a performer to ultimately entertain the hacker and to be humiliated. His free will has been taken away from him by an omnipotent, invisible entity.

The omnipotence of this hacker makes it difficult to imagine the person as an individual, given that the hacker is all seeing, all-knowing, capable of dictating one's action despite all the hacker has is personal information. The unclear identity of the person sending the texts leads to an ominous, uncomfortable feeling since Kenny and the audience can only see words on screen. Simply worded, without the context it may have been innocent but being put together, it is 
devastating to anybody on the receiving end.

The hacker, or hackers, pluralize their identity, to reinforce the idea of Kenny's tasks being a performance. He is no longer watched by an individual, he is acting in front of audience, one who is cruel, unremorseful and unresponsive except for their demands. This could also imply that he is being watched in multiple locations too since it is certainly plausible that most people in current society carry a camera which enables them to record activities and display such actions on screen, built in into their pockets.

Due to the audience or Kenny's inability to see the human element of the hacker, we see the technology as the one that controls him instead of individual controlling other persons. As indicated earlier, it is questionable if the people being blackmailed can indeed ignore the instructions but with the threat of constant surveillance, they are forced to do their tasks regardless if there is someone watching or not, a concept of surveillance to control individuals similar to the concept of Panopticon, made famous by Foucault, to control the general masses (Foucault, 1995).

We see other people being in the same circumstances indicate that the process is being done simultaneously, indicating that this form of control can be massive assuming that everybody has a piece of information online that they would rather keep private and anybody could fall victim. Given the nature, a hacker can pick and choose selectively what exactly can be used to break and bend their victims.

\section{Conclusion}

Shut Up and Dance shows that Baudrillard's idea of simulated reality, where the people are controlled by signs and symbols, is taking a more tangible form with the help of what Castell called as "real virtuality." The creation of the 'real virtuality' reinforces the idea of the controlling signs and symbols. Notably, the space is always on and has memories and has been networked widely (Castell, 1996). Signs and symbols distributed in the internet have more power than ever before. 
In Shut Up and Dance, Kenny's action which leads him to his demise is not the crime of being a pedophile itself, but rather his option to do it on the internet. Being caught doing a conduct against society's discourse on the internet, he is forced to do actions he is not willing to do in real life by signs and symbols he is receiving from the hacker whom Kenny himself is not sure who the person is or even whether it is actually a real person or a robot, an artificial intelligence. Receiving the threat of being socially cornered and shunned in real life from the hacker through sharing the evidence of his misconduct to his contact list, Kenny is determined to complete his tasks. The norm and discourse of the real space are adopted to the virtual space, making them intertwine and be affected by each other in a real way. The episode presents the idea of simulated reality by making Kenny as a puppet whose actions are dictated by his phone. By not revealing any information and details about the person or people behind Kenny's ordeal, the episode reinforces the idea that Kenny is not a slave to someone else but rather to the technology that he subscribes to. 


\section{References}

Barthes, R. (1964). Elements of Semiology. In Elements of Semiology. https://doi.org/10.1007/s13398-014-0173-7.2

Baudrillard, J. (1981). Simulacra and Simulation. Idea. https://doi.org/10.1017/S1359135500001081

Boren, A. (2015). A Rhetorical Analysis of Black Mirror: Entertaining Reflections of Digital Technology's Darker Effects. URJ-UCCS: Undergraduate Research Journal at UCCS.

Brooker, C. (2011). Black Mirror. Black Mirror. https://doi.org/cb-pdf

Castell, M. (1996). The Rise of the Network Society - The Information Age: Economy, Society, and Culture. Oxford-UK: Wiley-Blackwell.

Foucault, M. (1995). Discipline \& Punish ( 1975 ), Panopticism. Vintage Books (Extract).

Genosko, G. (2010). Baudrillard and Signs. Baudrillard and Signs. https://doi.org/10.4324/9780203201145

Kimble, H. J. (2008). The quantum internet. Nature. https://doi.org/10.1038/nature07127

Nolte-Odhiambo, C. (2019). Through the Black Mirror: Innocence, Abuse, and Justice in "Shut Up and Dance.” https://doi.org/10.1007/978-981-13-6210-1_5

Robinson, J., \& Brooker, C. (2016). Charlie $\{$ Brooker\}: ' $\{$ The $\}$ more horrible an idea, the funnier $\{I\}$ find it.' The Guardian.

Sculos, B. W. (2017). Screen Savior: How Black Mirror Reflects the Present More than the Future. Class Race Corporate Power. https://doi.org/10.25148/CRCP.5.1.001673

Singh, G. (2014). Recognition and the image of mastery as themes in Black Mirror (Channel 4, 2011-present): an eco-Jungian approach to "always-on" culture. International Journal of Jungian Studies. https://doi.org/10.1080/19409052.2014.905968. 